\title{
Laboratory preparedness in EU/EEA countries for detection of novel avian influenza A(H7N9) virus, May 2013
}

E Broberg (eeva.broberg@ecdc.europa.eu)1, D Pereyaslov², M Struelens³, D Palm³, A Meijer ${ }^{4}$, J Ellis ${ }^{5}$, M Zambon $^{5}$, J McCauley ${ }^{6}$, R Daniels ${ }^{6}$

1. Surveillance and Response Support, European Centre for Disease Prevention and Control (ECDC), Stockholm, Sweden

2. World Health Organization Regional Office for Europe (WHO/Euro), Copenhagen, Denmark

3. Microbiology Coordination section, European Centre for Disease Prevention and Control (ECDC), Stockholm, Sweden

4. Division of Virology, Centre for Infectious Disease Research, Diagnostics and Screening, National Institute for Public Health and the Environment (RIVM), Bilthoven, the Netherlands

5. Public Health England (PHE) Microbiology Services - Colindale, London, United Kingdom

6. World Health Organization (WHO) Collaborating Centre for Reference and Research on Influenza, Medical Research Council (MRC) National Institute for Medical Research (NIMR), Mill Hill, London , United Kingdom

Citation style for this article:

Broberg E, Pereyaslov D, Struelens M, Palm D, Meijer A, Ellis J, Zambon M, McCauley J, Daniels R. Laboratory preparedness in EU/EEA countries for detection of novel avian influenza A(H7N9) virus, May 2013. Euro Surveill. 2014;19(4):pii=20682. Available online: http://www.eurosurveillance.org/ViewArticle. aspx?Articleld $=20682$

Article submitted on 29 August 2013 / published on 30 January 2014

Following human infections with novel avian influenza $\mathrm{A}\left(\mathrm{H}_{7} \mathrm{~N} 9\right)$ viruses in China, the European Centre for Disease Prevention and Control, the World Health Organization (WHO) Regional Office for Europe and the European Reference Laboratory Network for Human Influenza (ERLI-Net) rapidly posted relevant information, including real-time RT-PCR protocols. An influenza RNA sequence-based computational assessment of detection capabilities for this virus was conducted in 32 national influenza reference laboratories in 29 countries, mostly WHO National Influenza Centres participating in the WHO Global Influenza Surveillance and Response System (GISRS). Twentyseven countries considered their generic influenza $A$ virus detection assay to be appropriate for the novel $\mathrm{A}\left(\mathrm{H}_{7} \mathrm{N9}\right)$ viruses. Twenty-two countries reported having containment facilities suitable for its isolation and propagation. Laboratories in 27 countries had applied specific $\mathrm{H}_{7}$ real-time RT-PCR assays and 20 countries had $\mathrm{N} 9$ assays in place. Positive control virus RNA was provided by the WHO Collaborating Centre in London to 34 laboratories in 22 countries to allow evaluation of their assays. Performance of the generic influenza $A$ virus detection and $\mathrm{H}_{7}$ and $\mathrm{N}_{9}$ subtyping assays was good in 24 laboratories in 19 countries. The survey showed that ERLI-Net laboratories had rapidly developed and verified good capability to detect the novel $A\left(\mathrm{H}_{7} \mathrm{~N} 9\right)$ influenza viruses.

\section{Introduction}

On 31 March 2013, Chinese authorities announced the identification of a novel reassortant $A\left(\mathrm{H}_{7} \mathrm{~N} 9\right)$ influenza virus isolated from three unlinked fatal cases of severe respiratory disease in eastern China. A few small clusters had been detected but no sustained human-to-human transmission had been observed [1]
The Chinese Center for Disease Control and Prevention (CCDC) subtyped and sequenced the novel viruses and showed them to be low-pathogenic viruses of avian origin [2]. This is the first time that human infection with avian influenza $\mathrm{A}\left(\mathrm{H}_{7} \mathrm{~N} 9\right)$ virus and human deaths due to a low-pathogenicity avian influenza virus have been identified [3]. As of 24 January 2014, 225 laboratory-confirmed human cases including 55 deaths had been reported from eight neighbouring provinces, two municipalities, the Hong Kong Special Administrative Region and Taiwan [4].

Detailed genetic sequence data from human, avian and environmental specimens and isolates of the novel avian influenza $\mathrm{A}\left(\mathrm{H}_{7} \mathrm{~N} 9\right)$ viruses have been made available through the Global Initiative on Sharing All Influenza Data (GISAID) EpiFlu database and the International Nucleotide Sequence Database Collaboration (INSDC). These data suggest that multiple reassortment events have taken place, potentially involving wild birds $[2,5-7]$. The six RNA segments encoding the internal proteins of the outbreak virus are closely related to avian $\mathrm{A}\left(\mathrm{H}_{9} \mathrm{~N}_{2}\right)$ viruses recently isolated from poultry in China, while, the segment encoding haemagglutinin ( $\mathrm{HA}$ ) belongs to the Eurasian $\mathrm{A}\left(\mathrm{H}_{7}\right)$ avian influenza virus lineage, and the segment for neuraminidase (NA) is most similar to those present in avian $\mathrm{A}\left(\mathrm{H}_{11} \mathrm{~N} 9\right)$ and $\mathrm{A}\left(\mathrm{H}_{7} \mathrm{~N} 9\right)$ viruses $[2,5-7]$. However, the nearest matches found for $\mathrm{HA}$ and NA are considerably less related than the nearest matches found for the six RNA segments encoding the internal proteins. This distinguishes the outbreak viruses from previously isolated avian influenza $\mathrm{A}\left(\mathrm{H}_{7} \mathrm{~N} 9\right)$ viruses, including those reported in birds in Europe. The sequence diversity observed between different isolates of the novel influenza $\mathrm{A}\left(\mathrm{H}_{7} \mathrm{~N} 9\right)$ virus, compared with historical data, suggests circulation of 


\section{TABLE 1}

Laboratories participating in the sequence-based survey exercise for detection of the novel avian influenza A(H7N9) virus, May 2013 ( $n=32$ laboratories in 29 countries)

\begin{tabular}{|c|c|}
\hline Organisation name and city & Country \\
\hline Medical University Vienna, Vienna & Austria $a^{a, b}$ \\
\hline Scientific Institute of Public Health, Brussels & Belgium ${ }^{\mathrm{a}, \mathrm{b}}$ \\
\hline National Centre of Infectious and Parasitic Diseases, Sofia & Bulgaria \\
\hline National Institute of Public Health, Prague & Czech Republic ${ }^{\mathrm{a}, \mathrm{b}}$ \\
\hline Nicosia General Hospital, Nicosia & Cyprus \\
\hline Statens Serum Institut, Copenhagen & Denmark $^{\mathrm{a}, \mathrm{b}}$ \\
\hline Health Board, Tallinn & Estonia \\
\hline National Institute for Health and Welfare, Helsinki & Finland ${ }^{a, b}$ \\
\hline Centre Hospitalier Lyon Sud, Lyon & France $^{a, b}$ \\
\hline Pasteur Institute of Paris, Paris & France $^{\mathrm{a}, \mathrm{b}}$ \\
\hline Robert Koch Institute, Berlin & Germany $^{\mathrm{a}, \mathrm{b}}$ \\
\hline National Centre for Epidemiology, Budapest & Hungary \\
\hline National University Hospital of Iceland, Reykjavík & Iceland ${ }^{\mathrm{a}}$ \\
\hline University College Dublin, Dublin & Ireland $d^{a, b}$ \\
\hline Istituto Superiore di Sanità, Rome & Italy ${ }^{a, b}$ \\
\hline State Agency Infectology Centre of Latvia, Riga & Latvia \\
\hline Centre for Communicable Diseases and AIDS, Vilnius & Lithuaniaa,b \\
\hline Laboratoire National de Santé, Luxembourg & Luxembourga,b \\
\hline National Institute for Public Health and the Environment (RIVM), Bilthoven & The Netherlands ${ }^{a, b}$ \\
\hline Norwegian Institute of Public Health, Oslo & Norway $^{\mathrm{a}, \mathrm{b}}$ \\
\hline Pathology laboratory, Sptar Mater Dei, Msida & Malta \\
\hline National Influenza Center, Warsaw & Polanda \\
\hline $\begin{array}{l}\text { National Institute of Research and Development for Microbiology and Immunology Cantacuzino, } \\
\text { Bucharest }\end{array}$ & Romania \\
\hline Public Health Authority of the Slovak Republic, Bratislava & Slovakia $^{a}$ \\
\hline Institute for Public Health, Ljubljana & Slovenia ${ }^{a, b}$ \\
\hline National Centre for Microbiology, Barcelona & Spain \\
\hline National Centre for Microbiology, Madrid & Spain ${ }^{a, b}$ \\
\hline Swedish Institute for Communicable Disease Control, Solna & Sweden ${ }^{a, b}$ \\
\hline Public Health England, Colindale & United Kingdom-England a,b \\
\hline Specialist Virology Centre for Wales, Cardiff & United Kingdom-Wales \\
\hline
\end{tabular}

a Laboratories in these 22 countries received $\mathrm{A} /$ Anhui/1/2013 positive control materials from the World Health Organization Collaborating Centre (WHO CC) in London.

b Laboratories based in these 19 countries returned real-time RT-PCR results based on the novel avian influenza A(H7N9) vRNA standard dispatched by WHO CC London and, in addition, the West of Scotland Specialist Virology Centre, Glasgow, Scotland (UK) provided experimental RT-PCR results.

the virus in birds before recent multiple introductions to humans [8]. The reservoir for this novel infection remains unknown, but the virus has been detected in domestic birds at live markets in eastern China [9].

It is recognised that real-time RT-PCR assays are at the forefront of influenza virus detection, with generic assays based on the matrix (M) gene for identification of influenza $A$, and specific assays for the HA and NA genes for identification of the different subtypes
[10]. According to a survey conducted in July 2011, the majority of European national influenza reference laboratories ( 31 laboratories in 25 countries) are using generic RT-PCR tests based on the influenza $A$ virus $M$ gene [11], which have the potential to detect also the novel $\mathrm{A}\left(\mathrm{H}_{7} \mathrm{~N} 9\right)$ viruses.

To assist European laboratories in verifying and ensuring their diagnostic capability to detect and identify the novel avian influenza $A\left(\mathrm{H}_{7} \mathrm{~N} 9\right)$ viruses, the 


\begin{tabular}{|l|c|c|}
\hline Capability & $\begin{array}{c}\text { Countries } \\
n\end{array}$ & $\begin{array}{c}\text { Laboratories } \\
n\end{array}$ \\
\hline Generic detection assay for influenza A is predicted to detect influenza A(H7N9) & 27 & 30 \\
\hline Have BSL3 laboratory facilities that they can use for culture of this virus & 27 & 29 \\
\hline Have isolation capability & 22 & 24 \\
\hline Influenza A(H) subtyping available & 27 & 29 \\
\hline Influenza A(N9) subtyping available & 20 & 22 \\
\hline
\end{tabular}

BSL: biosafety level.

European Centre for Disease Prevention and Control (ECDC), jointly with the World Health Organization (WHO) Collaborating Centre for Reference and Research on Influenza (WHO CC) in London, other members of the European Reference Laboratory Network for Human Influenza (ERLI-Net) and the WHO Regional Office for Europe (WHO/Europe), has released a technical briefing note on diagnostic preparedness in Europe for detection of the novel avian influenza $A\left(\mathrm{H}_{7} \mathrm{~N} 9\right)$ viruses [12]. The briefing note provides a list of considerations to ensure European-wide diagnostic capability, an update on currently available methods used for molecular detection of human infection with the novel avian influenza $A\left(\mathrm{H}_{7} \mathrm{~N} 9\right)$ virus by real-time RT-PCR, a table of validation criteria for $\mathrm{A}\left(\mathrm{H}_{7}\right) \mathrm{HA}$ molecular assays, and information on positive controls for RT-PCR assays.

To complement the technical briefing note, we conducted a questionnaire-based survey with the objective of assessing the capability (but not assessing the detection capacity in terms of numbers over time) of EU/EEA countries to detect and subtype the novel avian influenza $A\left(\mathrm{H}_{7} \mathrm{~N}_{9}\right)$ viruses, given the possibility of their spread to Europe. Subsequently, all influenza reference laboratories were offered positive control material by WHO CC London to verify and to report on the experimental sensitivity of their RT-PCR assays.

\section{Methods}

The survey questionnaire was developed jointly by ECDC, the ERLI-Net coordination team and WHO/Europe upon request of the European Commission. It was distributed to all ECDC influenza surveillance laboratory contact points (ERLI-Net laboratories) in May 2013. The questionnaire asked questions related to the current capability of the countries to detect the novel $A\left(\mathrm{H}_{7} \mathrm{~N} 9\right)$ viruses and their prediction, based on influenza RNA sequence analysis, regarding the need to update their detection primer sets. It also included questions asking for details of the primer sets in use and for the countries' capability to isolate and propagate influenza $\mathrm{A}\left(\mathrm{H}_{7} \mathrm{~N} 9\right)$ viruses.
The WHO CC Beijing supplied A/Anhui/1/2013(H7N9) to the WHO CC London as a virus stock that had been passaged twice in embryonated hens' eggs (E2) in compliance with the WHO Pandemic Influenza Preparedness (PIP) framework [13]. A single preparation of viral RNA (vRNA) was made from a virus stock that had been passaged once more in eggs (E2/E1) and grown to an HA titre of $256 / 512$ as assessed with turkey red blood cells. This virus stock yielded a concentration of $2 \times 10^{9}$ plaque forming units (PFU)/mL on Madin-Darby canine kidney (MDCK) cells. vRNA was extracted with a QIAamp vRNA extraction kit (Qiagen, catalogue no. \#52906), and each influenza reference laboratory was supplied with $40 \mu \mathrm{L}$ of an undiluted vRNA standard via dry-ice shipment. From the above data, it was calculated that $5 \mu \mathrm{L}$ (the amount commonly used in a $25 \mu \mathrm{L}$ real-time RT-PCR assay) of a $10^{-8}$ dilution of the VRNA standard would contain between 2.4 and 24 VRNA copies, assuming that 1 PFU equates to $10-100$ virus particles. Laboratories were asked to share with WHO CC London the results they generated with the vRNA standard in their existing or recently implemented real-time RT-PCR assays for generic influenza A virus detection and $\mathrm{H}_{7} \mathrm{~N} 9$ subtyping (including information on primer sets, RT-PCR kits and thermocycler platforms/cycling parameters, and dilution(s) of vRNA tested).

\section{Results}

Sequence-based analysis questionnaire

Thirty-two of 36 laboratories in 29 Member States of the European Union and European Economic Area (EU/ EEA) responded to the questionnaire within a month (Table 1).

Thirty laboratories in 27 countries predicted that their $M$ gene-based generic detection assay for influenza $A$ virus would also detect the novel $A\left(\mathrm{H}_{7} \mathrm{~N} 9\right)$ viruses (Table 2). One laboratory considered their generic influenza A RT-PCR detection assay inappropriate for detecting the novel virus. One laboratory indicated use of a commercial influenza $A$ detection assay, but not 
TABLE 3

Testing results with the novel avian influenza A(H7N9) vRNA standard in real-time RT-PCR assays, May 2013 (n=24 laboratories in 19 countries)

\begin{tabular}{|c|c|c|c|c|}
\hline \multicolumn{2}{|l|}{ Positive control (vRNA) dispatch } & \multicolumn{2}{|c|}{ Number of laboratories } & Countries represented \\
\hline \multicolumn{2}{|l|}{ Acknowledged receipt of vRNA } & \multicolumn{2}{|r|}{32} & 22 \\
\hline \multicolumn{2}{|c|}{ Tested primer/probe protocols with the vRNA } & \multicolumn{2}{|r|}{24} & 19 \\
\hline $\begin{array}{l}\text { Number of laboratories reporting } \\
\text { (number of assays carried out) }\end{array}$ & $\begin{array}{l}\text { Number of } \\
\text { countries }\end{array}$ & $\begin{array}{l}\text { Number of different } \\
\text { assays }\end{array}$ & Product size range & $\begin{array}{l}\text { Number of reports on end } \\
\text { point titrations (range of } \\
\text { end points reported) })^{1}\end{array}$ \\
\hline \multicolumn{5}{|l|}{ M gene (generic influenza $A$ assay) } \\
\hline $19^{b}$ & 16 & 8 & $77-205$ & $6\left(10^{-7}-10^{-9}\right)$ \\
\hline \multicolumn{5}{|l|}{ H7-HA gene } \\
\hline $24(33)^{c}$ & 19 & 16 & $52-254$ & $10\left(10^{-7}-10^{-9}\right)$ \\
\hline \multicolumn{5}{|l|}{ Ng-NA gene } \\
\hline $16(17)^{d}$ & 15 & 6 & $107-153$ & $4\left(10^{-6}-10^{-7}\right)$ \\
\hline
\end{tabular}

HA: haemagglutinin; M: matrix protein; NA: neuraminidase.

a The number of reports that included end point titrations is given, with the titration range for the assays in brackets).

b The most commonly used assay (six of 19 reports) was the InfA primer set from the United States Centers for Disease Control and Prevention (US CDC) in Atlanta [17]. The other assays were developed locally.

Seven laboratories in different countries reported using more than one primer set: Austria $(n=2), B e l g i u m(n=2), G e r m a n y(n=4)$, Italy $(n=2)$, Luxembourg $(n=2)$, the Netherlands $(n=2)$, and Norway $(n=2)$, generating 33 reports.

d Germany tested two primer sets, and 12 of the 17 reports were for the CCDC [15] N9 primer set.

knowing the primer sequences, was unable to predict its diagnostic capability.

It is recommended by WHO that the novel $\mathrm{A}\left(\mathrm{H}_{7} \mathrm{~N} 9\right)$ viruses be propagated in biosafety level (BSL) 3 facilities [14]; 29 laboratories in 27 countries reported having such facilities. Seven countries (Bulgaria, Cyprus, Estonia, Ireland, Malta, Romania and Slovenia) and Wales (United Kingdom (UK)), indicated that they would not propagate the novel $\mathrm{A}\left(\mathrm{H}_{7} \mathrm{~N}_{9}\right)$ virus in their laboratories because they lacked capability in their BSL3 facilities.

Twenty-nine influenza reference laboratories in 27 countries indicated having a real-time RT-PCR assay for $\mathrm{H}_{7}$ subtyping in place. Nine laboratories in eight countries had implemented subtyping assays based on $\mathrm{H}_{7}$ primers and probes developed by CCDC [15] or Corman et al. [16] or their own primer/probe sets based on sequence alignments. Fourteen laboratories in 13 countries had more than one $\mathrm{H}_{7}$ subtyping assay in place which showed some variation (within 1 log; cycle threshold $(\mathrm{Ct}): 3.2)$ in the sensitivity of detection of the novel avian influenza $\mathrm{A}\left(\mathrm{H}_{7} \mathrm{~N} 9\right)$ viruses. Eight laboratories in eight countries had implemented the complete protocol of the United States Centers for Disease Control and Prevention (US CDC) [17]. Four were using other alternative assay protocols than the ones listed here, for example those of Slomka et al. [18].

Twenty-two laboratories in 20 countries had set up $\mathrm{N9}$ subtyping at the time of the survey (May 2013). Ten laboratories in nine countries indicated that they had not yet tested their protocol or did not have this test. Thirteen countries had chosen to use the CCDC [15] assay with the primers and probes for $\mathrm{N}_{9}$ from that protocol. Seven laboratories in six countries had developed their own assay, and three laboratories used the primers and probes described by Corman et al. [16]. One country indicated that they would sequence the NA gene instead of setting up a specific subtyping realtime RT-PCR assay for $\mathrm{N}$.

To share viruses with a WHO CC and the WHO GISRS, 22 laboratories in 19 countries reported use of the WHO shipment fund for shipments to WHO CC London in the influenza season and during emerging outbreaks. Four countries used their own budgets with additional WHO shipment funding, and eight laboratories from eight countries used only their own budget. Three countries and laboratories indicated use of Quality Assurance Exercises and Networking on the Detection of Highly Infectious Pathogens (http://www.quandhip.info/) for shipments, in addition to the WHO shipment fund, and none of the responding laboratories indicated further need for financial support for sample shipment.

Use of positive control and sensitivity of RT-PCR assays

Having been alerted to the availability of $A /$ Anhui/1/2013-derived positive controls for their detection assays, 35 laboratories in 22 countries requested and received material from the WHO CC London. Twenty-one of these laboratories, three of which 
participate in the OFFLU OIE/FAO network of expertise on animal influenza (one each in Germany, Italy and the UK), received live virus and VRNA, 11 laboratories received VRNA only, and three laboratories received inactivated virus. Three further countries confirmed that they would receive or had received the US CDC kit including the corresponding positive controls (catalogue no. 1257 and 1258, available from the Influenza Reagent Resource, https://www.influenzareagentresource.org/). Two laboratories indicated that they needed assistance in setting up relevant assays, and they received individual support from WHO CC London.

The 24 laboratories (19 countries) that subsequently reported their results on detecting the novel influenza $\mathrm{A}\left(\mathrm{H}_{7} \mathrm{~N} 9\right)$ vRNA standard in their real-time RT-PCR protocols, had correctly predicted their capability to detect the novel virus (Table 3). Nineteen laboratories reported on generic influenza $A$ virus detection, all used real-time RT-PCR assays based on the $M$ gene. Eight different assays were employed that generated product sizes in the range 77-205 nt, and six of 19 reports employed the US CDC InfA primer set (106 nt PCR product). The six end point titration results all showed good sensitivity (five were positive for dilutions in the range $10^{-7}-10^{-8}$ and one laboratory showed positivity up to $10^{-9}$ ), five of them with the US CDC InfA primer set.

$\mathrm{H} 7$ detection was reported by all 24 laboratories (Table 3). Sixteen different $\mathrm{H}_{7}$ assays were employed, generating PCR fragments in the range 52-254 nt. The primer sets spanned five different regions in the HA gene, two in $H_{1}$, one spanning the $H_{1} / 2$ cleavage site, and two in HA2. Seven laboratories in different countries reported on more than one primer set, resulting in 33 individual primer set reports, 19 of which employed the following primer sets: CCDC HA1 [15] $(n=10)$, Slomka et al. HA2 [18] $(n=4)$, Corman et al. HA2 [16] $(n=3)$, and US CDC HA2 [17] $(n=2)$. The remaining reports used primers developed in-house or modifications of the primers listed here above, making them more specific for the novel avian influenza $\mathrm{A}\left(\mathrm{H}_{7} \mathrm{~N} 9\right)$. The $10 \mathrm{H}$ end point titrations, all of which showed good sensitivity (nine were positive for dilutions in the range $10^{-7}-10^{-8}$ and one laboratory showed positivity up to $10^{-9}$ ), were using among others the CCDC HA1 [15] $(n=3)$, Slomka et al. HA2 [18] $(n=2)$, Corman et al. HA2 [16] $(n=2)$ and the US CDC HA2 [17] $(n=1)$ primer sets.

Sixteen laboratories reported on $\mathrm{N} 9$ detection (Table 3). Six assays were employed (PCR product size range: 107-153 nt), two of which were the initial and modified versions of the CCDC assay. Twelve reports employed one of the CCDC N9 primer sets. Of the four $\mathrm{N} 9$ end point titrations, three employed a CCDC primer set (PCR product size $107 \mathrm{nt}$ ), while the fourth employed an assay developed in-house (RIVM, the Netherlands, product size: $125 \mathrm{nt}$ ); both $\mathrm{N} 9$ assays were less sensitive than the generic ( $M$ gene) and $\mathrm{H}_{7}$ assays, with end points at dilutions in the range $10^{-6}-10^{-7}$. One laboratory (NIC, Norway) obtained good sensitivity through end point titration $\left(10^{-8}-10^{-9}\right.$ for $\mathrm{M}$ and $\mathrm{H}_{7}$ but still only $10^{-6}-10^{-7}$ for $\mathrm{N}$ ) with real-time RT-PCRs set up using an AgPath-1D One-Step RT-PCR kit (Life Technologies) and run on Rotor-Gene 3000 or 6000 thermocyclers (Qiagen); this may be due to dilution of the vRNA standard with water containing carrier RNA as supplied with the QIAamp vRNA extraction kit (Qiagen).

A wide variety of RT-PCR kits and thermocycler platforms were used across the reporting laboratories for detection and subtyping of $A\left(\mathrm{H}_{7} \mathrm{~N} 9\right)$ viruses. Most laboratories used one-step RT-PCR kits from Life Technologies (TaqMan Fast Virus 1-Step, SuperScript III Platinum One Step qRT-PCR, AgPath-1D One-Step RT-PCR) or Qiagen (One-Step RT-PCR, Quantifast Probe RT-PCR), while some laboratories employed twostep systems (e.g. QuantiTect Reverse Transcription kit, Qiagen) developed in-house, and one laboratory reported on generic influenza $A$ detection as part of a multiplex assay. The various assays were implemented on Stratagene (MX3005), ABI (7300, 7500, 7500 FAST, $7900 \mathrm{HT}$ ), Rotor-Gene/Qiagen (Q, 3000, 6000), Roche (LC480) and Bio-Rad (CFX96) thermocyclers.

\section{Discussion}

ERLI-Net laboratories had built up detection capability for the novel influenza $A\left(\mathrm{H}_{7} \mathrm{~N} 9\right)$ viruses within approximately two months from the first reports of this virus. Most ERLI-Net laboratories had developed or applied specific $\mathrm{H}_{7}$ and/or $\mathrm{N} 9$ real-time RT-PCR assays to identify the novel $\mathrm{A}\left(\mathrm{H}_{7} \mathrm{Ng}\right)$ viruses: 27 countries have an $\mathrm{H}_{7}$ assay and 21 an $\mathrm{N} 9$ assay in place in their influenza reference laboratories. Overall, 28 of 31 laboratories in 27 countries reported an ability to subtype $\mathrm{A}\left(\mathrm{H}_{7}\right)$ viruses, with the remaining three laboratories proposing to send their non-subtypeable viruses to WHO CC London.

Overall, laboratories in EU/EEA countries appear to be well prepared for the detection and identification of the novel avian $A\left(\mathrm{H}_{7} \mathrm{~N} 9\right)$ influenza virus, because they either can detect the viruses themselves or, if not, have a mechanism in place to forward the viruses to WHO CC for characterisation. Furthermore, it is likely that the $\mathrm{H}_{7}$-specific $\mathrm{HA}_{2}$ primer set from the US CDC will be adopted by more laboratories, as it is now available through the Influenza Reagent Resource (https://www. influenzareagentresource.org \#FR-1258). Due to the high genetic diversity in the HA of influenza viruses of the $A\left(\mathrm{H}_{7}\right)$ subtype, it has not been possible to design a universal primer/probe set of the required specificity and sensitivity to detect all avian influenza $A\left(\mathrm{H}_{7}\right)$ viruses. However, both the US CDC H7- $\mathrm{HA}_{2}$ primer set [17] and the set by Slomka et al. [18] have been evaluated and are capable of detecting Eurasian $\mathrm{H}_{7}$ avian influenza viruses typically infecting poultry in Europe that have the potential to cause zoonoses.

From the survey responses and results reported on the use of an A/Anhui/1/2013(H7N9) vRNA standard, it is apparent that ERLI-Net laboratories across EU/ 
EEA countries have a range of assays available that are suitable for detecting the M, HA and NA genes of the novel $A\left(\mathrm{H}_{7} \mathrm{~N} 9\right)$ influenza virus. With current capabilities, these novel avian influenza $A\left(\mathrm{H}_{7} \mathrm{~N} 9\right)$ viruses would be detected in the majority of EU/EEA countries on submission of a sample to a national influenza reference laboratory for characterisation. However, as these $A\left(\mathrm{H}_{7} \mathrm{Ng}\right)$ viruses are likely to evolve, sequencebased comparison of primer/probe sets with circulating $\mathrm{H}_{7} \mathrm{~N} 9$ viruses should be part of a continuous monitoring practice in all influenza reference laboratories, with modification of set(s) as required. Despite such monitoring it is clear that, even when the same detection algorithm, equipment and laboratory protocols are used, the human factor plays a role in laboratory detection, and assay performance can only be verified through external quality assessment (EQA) and clinical validation [19]. ERLI-Net undertook an EQA in autumn 2013 that included an $\mathrm{A}\left(\mathrm{H}_{7} \mathrm{Ng}\right)$ virus in the panel; the results are pending.

\section{Conclusions}

This capability assessment would not have been possible without the prompt actions of the Chinese authorities and the CCDC who rapidly deposited sequence data in the GISAID database and provided virus for culture and RNA extraction to WHO CC London. Feedback from ERLI-Net laboratories indicates that EU/EEA countries have good detection capabilities for these novel avian influenza $A\left(\mathrm{H}_{7} \mathrm{~N} 9\right)$ viruses. Generally, this study illustrates the importance of having a coordinated laboratory network such as ERLI-Net, with a direct link to the WHO GISRS for virus and reagent sharing, and the usefulness of timely responses to sequence-based analysis surveys as well as testing of performance and proficiency to inform a regional risk management response.

A large diversity of assays and platforms for influenza detection and diagnosis are available in the European health sector, reflecting prevailing local conditions. Nevertheless, good technical performance can be achieved, even though a lack of detailed knowledge of primer and probe binding sites in commercial kits makes it difficult to predict their match with the viral target genes. The mechanism described here (a survey including sequence-based analysis followed by practical assessment) is likely to be necessary every time a new variant of influenza virus with pandemic potential emerges. During such surveys, clear technical communication channels both within and between countries, ERLI-Net/ECDC, WHO/Europe and WHO CC London, are a crucial part of preparedness and response.

In influenza reference laboratory networks, the existing pathways for specimen referral to the WHO CCS and annual EQAs have proven useful tools in ensuring good seasonal influenza surveillance. The same pathways can be used in an emergency. For EU/EEA countries, an additional element in an emergency response is enhanced communication between ECDC,
WHO/Europe, WHO CC London and other ERLI-Net virology experts, to ensure high quality and rapid technical support for the ERLI-Net laboratories. The network benefits from WHO CC functions through the distribution of positive controls for RT-PCR and support in the validation of protocols. Larger network laboratories, such as Public Health England Colindale, can support the network in the clinical validation of the detection assays. However, a sequence-based computational assessment of the detection platforms is not enough, and EQA of the assays is crucial to ensure the field validation of primers and reagents. This ERLI-Net model could be applied to other dedicated communicable disease networks to assess the performance of their schemes for sample referral, setup of detection assays and validation of the assays for emerging infectious disease events.

The current response to the emergence of influenza $A\left(\mathrm{H}_{7} \mathrm{~N} 9\right)$ has demonstrated a good preparedness in European influenza reference laboratories. Nevertheless, a number of areas can be improved: (i) how best to assess the detection assays used in the primary diagnostic laboratories, (ii) how well evaluated and clinically validated a detection protocol should be before it is shared with the network laboratories, (iii) where to post all technical material so that it can be easily found, (iv) how to speed up the distribution of positive controls, (v) the best way to communicate rapidly within the network, (vi) how the questionnaire results are followed up with the laboratories, and (vii) how the required training, based on EQA results, is delivered. Overall, there is a need to decide on a standard operation procedure for emergency responses in the network, so that all parties know their role(s) and timeline(s) for response and what is expected from them when a novel virus emerges. As the influenza $A\left(\mathrm{H}_{7} \mathrm{~N} 9\right)$ situation is still evolving, there is no reason for complacency, and preparedness at the European level will continue to be monitored. Gene sequences from the most recent influenza $\mathrm{A}(\mathrm{H} 7 \mathrm{~N} 9)$ zoonotic infections available in GISAID, as of 24 January 2014, indicate that the low levels of genetic drift observed are unlikely to adversely affect the detection capabilities that have been developed in EU/EEA countries .

Authors' contributions

$E B, R D, J M c C$ were responsible for the analyses of returned data and drafting of the manuscript. These authors and the others (JE, AM, DPa, DPe, MS and MZ) took part in discussions relating to the development and drafting of guidance for ERLI-Net/NIC laboratories and the sequence-based questionnaire, and critical review of the present manuscript.

Conflict of interest

None declared. 


\section{Acknowledgements}

The authors thank all persons in EU/EEA countries and their human influenza reference laboratories that responded to the sequence-based analysis questionnaire and the request for feedback on the use of positive control vRNA from a representative novel avian influenza $A\left(\mathrm{H}_{7} \mathrm{Ng}\right)$ virus shared with GISRS by WHO CC Beijing. The work of the WHO CC was supported by MRC programme U117512723.

\section{References}

1. Qi X, Qian YH, Bao CJ, Guo XL, Cui LB, Tang FY, et al. Probable person to person transmission of novel avian influenza A ( $\left.\mathrm{H}_{7} \mathrm{~N} 9\right)$ virus in Eastern China, 2013: epidemiological investigation. BMJ. 2013;347:f4752.

http://dx.doi.org/10.1136/bmj.f4752

2. Gao R, Cao B, Hu Y, Feng Z, Wang D, Hu W, et al. Human infection with a novel avian-origin influenza $A\left(\mathrm{H}_{7} \mathrm{~N} 9\right)$ virus. $\mathrm{N}$ Engl J Med. 2013;368(20):1888-97. http://dx.doi.org/10.1056/NEJMoa1304459

3. European Centre for Disease Prevention and Control (ECDC) Human infection with a novel avian influenza virus, $\mathrm{A}(\mathrm{H} / \mathrm{N} 9)$ - China. Stockholm: ECDC; 2013. Available from: http://www. ecdc.europa.eu/en/publications/Publications/influenza$\mathrm{A} \% 28 \mathrm{H}_{7} \mathrm{~N} 9 \% 29$-China-rapid-risk-assessment-8-may-2013.pdf

4. European Centre for Disease Prevention and Control (ECDC). Communicable disease threats. Stockholm: ECDC; 2014. Available from: http://www.ecdc.europa.eu/en/publications/ Publications/communicable-disease-threats-report-25jan-2014.pdf

5. Kageyama T, Fujisaki S, Takashita E, Xu H, Yamada S, Uchida $\mathrm{Y}$, et al. Genetic analysis of novel avian $\mathrm{A}\left(\mathrm{H}_{7} \mathrm{~N} 9\right)$ influenza viruses isolated from patients in China, February to April 2013. Euro Surveill. 2013;18(15):20453. Available from: http://www. eurosurveillance.org/ViewArticle.aspx?Articleld $=20453$

6. World Health Organization (WHO). Overview of the emergence and characteristics of the avian influenza $\mathrm{A}\left(\mathrm{H}_{7} \mathrm{N9}\right)$ virus. Geneva: WHO; 2013. Available from: http://www.who.int/ influenza/human_animal_interface/influenza_h7ng/WHO_ H7N9_review_31May13.pdf

7. Wu A, Su C, Wang D, Peng Y, Liu M, Hua S, et al. Sequential reassortments underlie diverse influenza $\mathrm{H}_{7} \mathrm{~N} 9$ genotypes in China. Cell Host Microbe. 2013;14(4):446-52. http://dx.doi.org/10.1016/j.chom.2013.09.001

8. Jonges M, Meijer A, Fouchier RA, Koch G, Li J, Pan IC, et al. Guiding outbreak management by the use of influenza $A\left(\mathrm{H}_{7} \mathrm{Nx}\right)$ virus sequence analysis. Euro Surveill. 2013;18(16):20460. Available from: http://www.eurosurveillance.org/ViewArticle. aspx?Articleld $=20460$

9. Shi JZ, Deng GH, Liu PH, Zhou JP, Guan LZ, Li WH, et al. Isolation and characterization of $\mathrm{H}_{7} \mathrm{~N} 9$ viruses from live poultry markets-Implication of the source of current $\mathrm{H}_{7} \mathrm{~N} 9$ infection in humans. Chin Sci Bull. 2013; 58(16). doi: 10.1007/ S11434-013-5873-4. http://dx.doi.org/10.1007/s11434-013-5873-4

10. Zhang WD, Evans DH. Detection and identification of human influenza viruses by the polymerase chain reaction. J Virol Methods. 1991 Jun;33(1-2):165-89. http://dx.doi.org/10.1016/0166-0934(91)90017-T

11. European Centre for Disease Prevention and Control (ECDC). CNRL in silico exercise to determine the capabilities of network laboratories to detect triple reassortant swine origin influenza $\mathrm{A}\left(\mathrm{H}_{3} \mathrm{~N}_{2}\right)$ viruses. Stockholm: ECDC; 2012 . Available from: http://ecdc.europa.eu/en/publications/Publications/1204-TERCNRL-Capability-Exercise.pdf

12. European Centre for Disease Prevention and Control (ECDC), Community Network of Reference Laboratories for Human Influenza in Europe, World Health Organization Regional Office for Europe. Diagnostic preparedness in Europe for detection of avian influenza $\mathrm{A}\left(\mathrm{H}_{7} \mathrm{~N}_{9}\right)$ viruses. Stockholm: ECDC; 2013. Available from: http://ecdc.europa.eu/en/publications/ Publications/Forms/ECDC_DispForm.aspx?ID=1103

13. World Health Organization (WHO). Pandemic influenza preparedness framework for the sharing of influenza viruses and access to vaccines and other benefits. Geneva: WHO; 2011 Available from: http://whqlibdoc.who.int/ publications/2011/9789241503082_eng.pdf

14. World Health Organization (WHO). Laboratory biorisk management for laboratories handling human specimens suspected or confirmed to contain avian influenza $\mathrm{A}\left(\mathrm{H}_{7} \mathrm{~N}_{9}\right)$ virus causing human disease. Interim recommendations. Geneva: WHO; 2013. Available from: http://www.who.int/
influenza/human_animal_interface/influenza_h7ng/InterimRe cLaboratoryBioriskManagementH7N9_10May13.pdf

15. World Health Organization (WHO) Collaborating Center for Reference and Research on Influenza at the Chinese National Influenza Center B, China. Real-time RT-PCR Protocol for the Detection of Avian Influenza A(H7N9) Virus. Geneva: WHO 2013. Available from: http://www.who.int/influenza/gisrs_ laboratory/cnic_realtime_rt_pcr_protocol_a_h7n9.pdf

16. Corman VM, Eickmann M, Landt O, Bleicker T, Brunink S, Eschbach-Bludau M, et al. Specific detection by real-time reverse-transcription PCR assays of a novel avian influenza $\mathrm{A}\left(\mathrm{H}_{7} \mathrm{N9}\right.$ ) strain associated with human spillover infections in China. Euro Surveill. 2013;18(16):20461. Available from: http:// www.eurosurveillance.org/ViewArticle.aspx?Articleld $=20461$

17. Centers for Disease Control and Prevention (CDC). Seasonal Influenza, Diagnostics for Detecting $\mathrm{H}_{7} \mathrm{~N} 9$ Using rRT-PCR. Atlanta: CDC. [Accessed latest 22 January 2014]. Available from: http://www.cdc.gov/flu/avianflu/h7ng/detectingdiagnostics.htm

18. Slomka MJ, Pavlidis T, Coward VJ, Voermans J, Koch G, Hanna A, et al. Validated RealTime reverse transcriptase PCR methods for the diagnosis and pathotyping of Eurasian $\mathrm{H}_{7}$ avian influenza viruses. Influenza Other Respi Viruses. 2009;3(4):151-64. http://dx.doi.org/10.1111/j.1750-2659.2009.00083.x

19. Meijer A, Beerens A, Claas E, Hermans M, de Jong A, Molenkamp R, et al. Preparing the outbreak assistance laboratory network in the Netherlands for the detection of the influenza virus $\mathrm{A}\left(\mathrm{H}_{1} \mathrm{~N}_{1}\right)$ variant. J Clin Virol. 2009;45(3):179-84. http://dx.doi.org/10.1016/j.jcv.2009.06.003 